\title{
Surto de raiva em morcegos frugívoros no município de Niterói, RJ, 2018
}

\author{
[Outbreak of rabies in frugivorous bats in the municipality of Niterói, RJ, 2018]
}

\section{"Relato de caso/Case Report"}

\author{
Flavio Fernando Batista Moutinho ${ }^{1,2 *}$, Viviane Moura Azevedo Nunes ${ }^{2}$, Paulo Mafra Fernandes ${ }^{2}$, \\ Fábio Villas Boas Borges ${ }^{2}$, Francisco de Faria Neto ${ }^{3}$
}

${ }^{1}$ Universidade Federal Fluminense (UFF) Niterói-RJ, Brasil.

${ }^{2}$ Centro de Controle de Zoonoses de Niterói-RJ, Brasil.

${ }^{3}$ Departamento de Vigilância Sanitária e Controle de Zoonoses (DEVIC) Niterói-RJ, Brasil.

*Autor para correspondência/Corresponding author: E-mail: flaviomoutinho@id.uff.br

\begin{abstract}
Resumo
A raiva é uma doença viral gravíssima que pode afetar todos os mamíferos. Trata-se de um estudo exploratório descritivo documental desenvolvido a partir dos dados do Centro de Controle de Zoonoses do município de Niterói, RJ. No mês de julho de 2018 ocorreram três casos de raiva em morcegos, diagnosticados por imunofluorescência direta e inoculação em camundongos, todos envolvendo Artibeus sp. e localizados numa pequena área do bairro São Francisco. O Centro de Controle de Zoonoses desenvolveu uma série de ações visando impedir a transmissão da doença para humanos e outras espécies de animais. Os resultados sugerem um possível surto de raiva em morcegos no bairro São Francisco, em julho de 2018. A ocorrência de um evento desse em um bairro da área urbana de uma metrópole pode ser considerado um fator preocupante pela possibilidade de ocorrência de casos da doença em humanos ou animais domésticos, principalmente tendo em vista a existência dos demais fatores condicionantes e determinantes da ocorrência da enfermidade encontrados no município. Nesse sentido, esforços devem ser envidados pelo poder público no sentido de eliminar ou mitigar tais fatores, visando salvaguardar a saúde da população.
\end{abstract}

Palavras-chave: Chiroptera; vigilância em saúde, zoonose.

\begin{abstract}
Rabies is a severe viral disease that can affect all mammals. This is an exploratory descriptive documentary study developed from the data of the Zoonoses Control Center of the city of Niterói, RJ. In July 2018, there were three cases of rabies in bats, diagnosed by direct immunofluorescence and inoculation in mice, all of them involving the species Artibeus sp. and located in a small area of the São Francisco neighborhood. The Zoonoses Control Center has developed a sequence of actions aimed at stopping the transmission of the disease to humans and other animal species. The results allow us to conclude that there was an outbreak of rabies in bats in the São Francisco neighborhood in July 2018. The occurrence of an event like this in a neighborhood in the urban area of a metropolis can be considered a worrying factor for the possibility of more cases of the disease in humans or domestic animals, especially considering the existence of other conditional factors and determinants of the occurrence of the disease found in the municipality. In this sense, efforts must be made by the public power to eliminate or mitigate such factors, in order to safeguard the health of the population.
\end{abstract}

Keywords: Chiroptera; health surveillance; zoonosis.

\section{Introdução}

A raiva é uma zoonose viral gravíssima que pode afetar todos os mamíferos, levando-os, invariavelmente, à morte. Os órgãos públicos de saúde vêm desenvolvendo, desde 1973, as ações previstas no Programa Nacional de Controle da Raiva, no qual pode-se destacar como principais medidas a vacinação de gatos e cães, a vigilância epidemiológica, o controle da população animal, o tratamento profilático de indivíduos expostos, o 
diagnóstico laboratorial e a educação em saúde (OPAS; BRASIL, 2002). Além disso, os órgãos de Defesa Sanitária devem realizar o monitoramento de abrigos de morcegos hematófagos, o controle da vacinação em animais de produção, o controle dos focos de raiva nesses animais e cuidar do sistema de informação e notificação (BRASIL, 2009).

No Brasil, a doença em humanos ainda ocorre esporadicamente, principalmente nas regiões nordeste e norte (BRASIL, 2018). A raiva animal é considerada endêmica no estado do Rio de Janeiro, mas não é diagnosticado nenhum caso da doença em cães ou gatos desde 2001 (Oliveira et al., 2010).

O processo de urbanização tem como uma de suas consequências ambientais a atração de morcegos para as áreas urbanas, onde conseguem alimento e abrigo para sobreviverem. Os morcegos são muito versáteis quanto à sua alimentação, havendo espécies insetívoras, carnívoras, nectarívoras, frugívoras, hematófagas. (BRASIL, 1988; BRASIL, 2009). Os morcegos insetívoros se alimentam de insetos atraídos pela iluminação urbana e os frugívoros, fitófagos e nectarívoros pela arborização das cidades (Uieda et al., 1995).

$\mathrm{O}$ vírus da raiva já foi identificado em pelo menos 41 espécies de morcegos no planeta (Sodré et al., 2010) e a raiva transmitida por morcegos vem aumentando sua importância epidemiológica a partir dos anos 2000 (OPAS; BRASIL, 2002). Esse quadro vem se repetindo no estado do Rio de Janeiro, como demonstrado por Oliveira et al. (2010).

A espoliação de humanos e animais por morcegos é relatada no estado do Rio de Janeiro desde pelo menos 1990 (Costa e Esbérard, 2011). Na região Metropolitana II, onde o município de Niterói está inserido, ela é contumaz (Moutinho et al., 2015). Há inclusive um relato recente de mordida de humano no bairro Sapê (Bernardes Filho et al., 2014).

O Centro de Controle de Zoonoses de Niterói (CCZ) recebe, anualmente, cerca de 25 reclamações da população envolvendo morcegos e, de acordo com Moutinho et al. (2018a), existe no município uma série de fatores determinantes e condicionantes que podem levar à ocorrência de casos de raiva humana ou em animais domésticos na cidade (Moutinho et al., 2018b).

O gênero Artibeus sp. pertence à família Phylostomidae, que é considerada endêmica no continente americano. Essa família é extremamente versátil na alimentação, podendo se alimentar de néctar, pólen, folhas, frutos, dentre outros (Brusco e Tozato, 2009). Esses morcegos são considerados dominantes em áreas degradadas e em áreas urbanas (Siqueira et al., 2016). Dentre os morcegos mais frequentes na região do estudo, encontra-se a espécie A. lituratus (Niterói, 2003). Estudo de Cabral et al. (2012) mostrou a predominância de morcegos desse gênero nos casos de raiva em quirópteros diagnosticados no município do Rio de Janeiro. Morcegos do gênero Artibeus sp. são frequentes em áreas urbanas. Considerados morcegos de grande porte, têm papel fundamental na dispersão de sementes e recuperação de florestas, já que têm o hábito de fazer uso de abrigo noturno em árvores diferentes de onde subtraem os frutos (Zortéa, 2007). Vale ressaltar, que a quiropterocoria de sementes de árvores nativas é uma das maneiras mais frequentes de dispersão de sementes em áreas urbanas, exatamente pela presença crescente dos morcegos nas cidades (Siqueira, 2017).

Assim sendo, o presente trabalho objetivou descrever e analisar um surto de raiva em morcegos ocorrido no bairro São Francisco, no município de Niterói, RJ, em 2018. Trata-se de um estudo exploratório descritivo documental, desenvolvido a partir de dados coletados no Centro de Controle de Zoonoses do município de Niterói, RJ.

\section{Descrição do Caso}

Ocupando uma área de 134,074 km², Niterói integra a Região Metropolitana do estado do Rio de Janeiro, tendo como limites o oceano Attântico, a baía da Guanabara e os municípios de São Gonçalo e Maricá. Sua população estimada para 2018 era de 511.786 habitantes (IBGE, 2019). O bairro São Francisco, por sua vez, pertence à região Praias da Baía, limitando-se com os bairros Icaraí, Vital Brazil, Santa Rosa, Viradouro, Cachoeira, Cafubá e Charitas, além da baía da Guanabara (Niterói, 2004), possui 3,4 km² de extensão e uma população de 9.712 habitantes em 2010 (IBGE, 2010).

Desde 2013 vêm sendo identificados no município de Niterói, casos esporádicos de raiva em morcegos, por intermédio da vigilância passiva realizada pelo Centro de Controle de Zoonoses. No período 2013 a 2017 foram três casos diagnosticados, nos bairros Barreto, Santa Rosa e Centro. Mas em 2018, somente em 11 dias 
do mês de julho, foram diagnosticados três morcegos com raiva, todos encontrados mortos no bairro São Francisco (Tabela 1). A distância entre os casos foi de 555 metros entre o primeiro e o segundo e 60 metros entre o segundo e o terceiro
(Figura 1). A proximidade espacial e temporal entre os casos sugere tratar-se de um surto, principalmente porque todos os morcegos foram identificados como do gênero Artibeus sp.

Tabela 1. Qualificação dos casos de raiva de quirópteros ocorridos no bairro São Francisco, Niterói, RJ, em julho de 2018.

\begin{tabular}{cccll}
\hline Caso & $\begin{array}{c}\text { Data da } \\
\text { coleta }\end{array}$ & $\begin{array}{c}\text { Identificação do } \\
\text { gênero }\end{array}$ & Logradouro & \multicolumn{1}{c}{ Caracterização do local da coleta } \\
\hline $1^{\circ}$ & $08 / 07 / 18$ & Artibeus sp. & Rua Bela Vista & $\begin{array}{l}\text { Na cama de um cão doméstico na varanda de uma } \\
\text { residência, próximo a uma árvore não identificada } \\
\text { embaixo da qual havia diversas sementes e frutos } \\
\text { parcialmente consumidos de amêndoa da praia } \\
\text { (Terminalia catappa) }\end{array}$ \\
\hline $2^{\circ}$ & $14 / 07 / 18$ & Artibeus sp. & Rua Tabajaras & $\begin{array}{l}\text { No logradouro público próximo a um exemplar de } \\
\text { Abieiro (Pouteria caimito) embaixo do qual havia } \\
\text { diversas sementes e frutos (abiu) parcialmente } \\
\text { consumidos. }\end{array}$ \\
\hline $3^{\circ}$ & $19 / 07 / 18$ & Artibeus sp. & $\begin{array}{l}\text { Av. Presidente } \\
\text { Roosevelt }\end{array}$ & $\begin{array}{l}\text { No logradouro público embaixo de um exemplar de } \\
\text { pau-ferro (Libidibia ferrea). }\end{array}$ \\
\hline
\end{tabular}

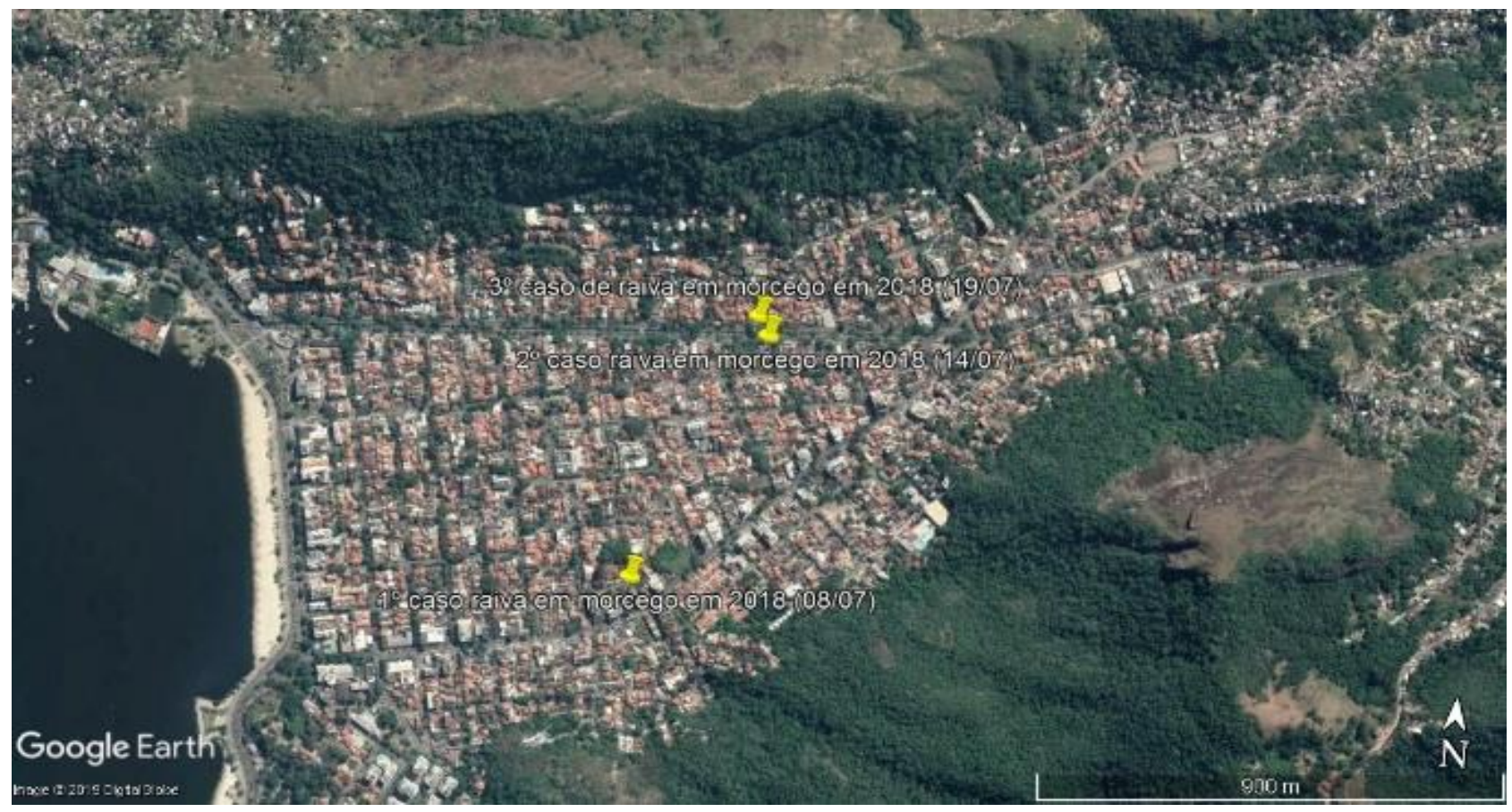

Figura 1. Localização dos casos de raiva em morcegos identificados pelo Centro de Controle de Zoonoses de Niterói, RJ, em julho de 2018.

A fim de evitar uma possível transmissão da raiva silvestre para animais domésticos e humanos do bairro, o Centro de Controle de Zoonoses efetuou uma série de ações após a detecção do primeiro caso de raiva em morcego em São Francisco.

A primeira iniciativa foi notificar os casos de óbitos de morcegos em área urbana ao serviço de epidemiologia do município. Em seguida foram visitados todos os estabelecimentos veterinários do bairro, num total de quatro, a fim de dar ciência aos médicos veterinários ali atuantes para a ocorrência dos casos de raiva. Assim, acredita-se ter aumentado a sensibilidade dos serviços de saúde animal para a detecção de um possível caso em animal doméstico, além de atualizar os profissionais quanto às medidas a serem tomadas no caso do contato de animais domésticos com morcegos. Nessas visitas, foi observado que somente em um dos 
estabelecimentos visitados havia vacina antirrábica animal, já que ocorria desabastecimento do produto pelos laboratórios produtores há alguns meses. Tal situação é grave, pois pode ter diminuído a quantidade de animais imunizados contra a doença no bairro.

$\mathrm{Na}$ sequência, foi feito o mapeamento dos casos e foi definido um perímetro ao redor de cada caso onde todos os imóveis foram visitados a fim de sensibilizar a população para o problema e, também, vacinar os cães e gatos porventura existentes (Figura 2). Nessa ação foram visitados 390 imóveis, sendo que houve 67 recusas de moradores em permitir a entrada da equipe. Foram vacinados 115 cães e 30 gatos, tendo havido 68 recusas de vacinação em cães e 07 em gatos, todas pelo fato dos animais já se encontrarem vacinados. Foi instalado, ainda, um posto de vacinação fixo funcionando em horário comercial no bairro, tendo funcionado até a realização da campanha de vacinação antirrábica, ocorrida em setembro de 2018. No posto fixo foram vacinados 94 cães e 56 gatos. Além disso, no primeiro caso, onde houve sabidamente contato de um cão com o morcego positivo, o animal foi revacinado e posto em observação pelo período de 180 dias na própria residência, tendo o tutor assinado um Termo de Responsabilidade.

Vale destacar que, ainda no mês de julho de 2018, foram registrados pelo CCZ no bairro de São Francisco, a cerca de 650 metros do terceiro caso, dois casos de espoliação de cães por morcegos hematófagos (Figura 3). Ambos os cães foram revacinados e colocados em observação domiciliar pelo período de 180 dias, tendo o tutor assinado um Termo de Responsabilidade. Esse prazo de isolamento e quarentena equivale ao tempo de incubação máximo do vírus da raiva em cães e serve para excluir o risco da doença ser transmitida para outros mamíferos caso o cão venha a desenvolvê-la (BRASIL, 2012).

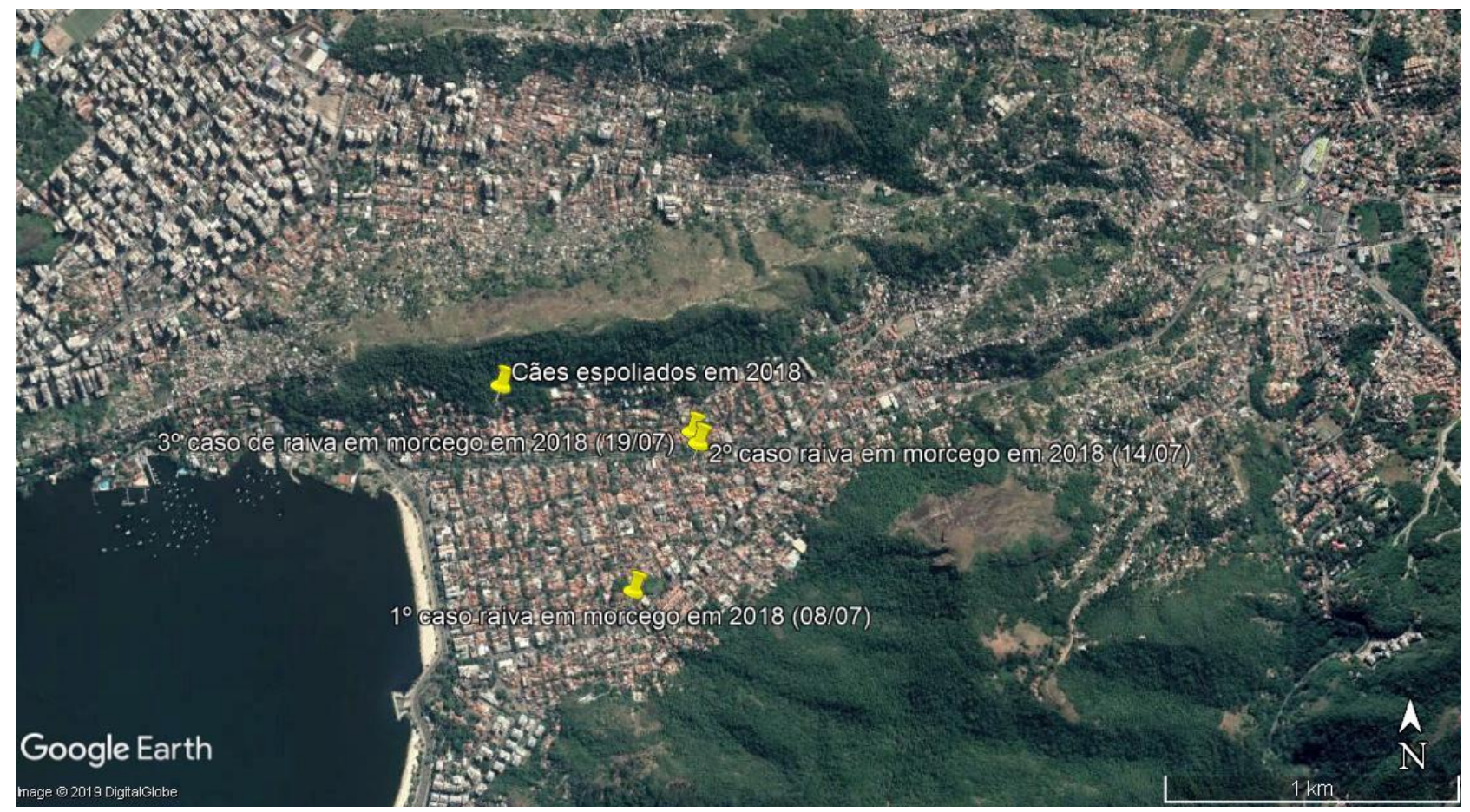

Figura 2. Localização do imóvel onde ocorreu espoliação de cães por morcego hematófago no bairro São Francisco, Niterói, RJ, 2018.

\section{Discussão}

Em áreas urbanas os morcegos buscam abrigos com características similares àquelas encontradas em ambientes silvestres, logo, as árvores urbanas estão entre os abrigos preferenciais para os quirópteros, especialmente os frugívoros (Pacheco et al., 2010).

$\mathrm{O}$ fato de no primeiro caso terem sido encontrados diversos frutos parcialmente consumidos e sementes de amêndoas da praia ( $T$. catappa) - espécie frequentemente presente na dieta dos morcegos frugívoros - sob uma árvore de outra espécie é um indicativo da utilização da mesma como abrigo noturno ou digestório. Tais abrigos são utilizados por espécies frugívoras de morcegos durante o período da noite para o consumo das frutas e, após isso, os quirópteros retornam para o abrigo diurno, onde passam a 
maior parte do tempo (BRASIL, 1988). No segundo caso, o abieiro ( $P$. caimito) pertence à Família Sapotaceacea, uma das principais no que diz respeito ao uso alimentar por morcegos (Van der Pijl, 1972).

No que diz respeito ao terceiro caso, o morcego foi encontrado morto sob um exemplar de L. ferrea (Família Febaceae, Subfamília Caesalpinioideae). Trata-se de uma espécie comumente utilizada na arborização urbana (Maia-Silva et al., 2012; Siqueira, 2017) mas não foi encontrado relato do uso alimentar da espécie por morcegos. Mas não se pode descartar seu uso como abrigo noturno e, também, a possibilidade do quiróptero ter vindo a óbito no local sem qualquer relação com a espécie arbórea encontrada no local. Em todos os casos o diagnóstico foi feito pela técnica de imunofluorescência direta e confirmado pela prova biológica, com inoculação intracerebral em camundongos de suspensão de tecido nervoso suspeito. Geograficamente, o bairro de São Francisco tem um formato de vale, sendo cercado pelos morros do Cavalão e da Viração. Trata-se de uma região com grande área de mata, inclusive englobando parte do Parque Municipal de Niterói - PARNIT, o que pode ser um facilitador para a presença dos morcegos. De acordo com Bianconi et al. (2006), mesmo pequenos fragmentos de floresta são importantes para a manutenção dos morcegos, pela disposição espacial facilitar o uso ou pela disponibilização de recursos.

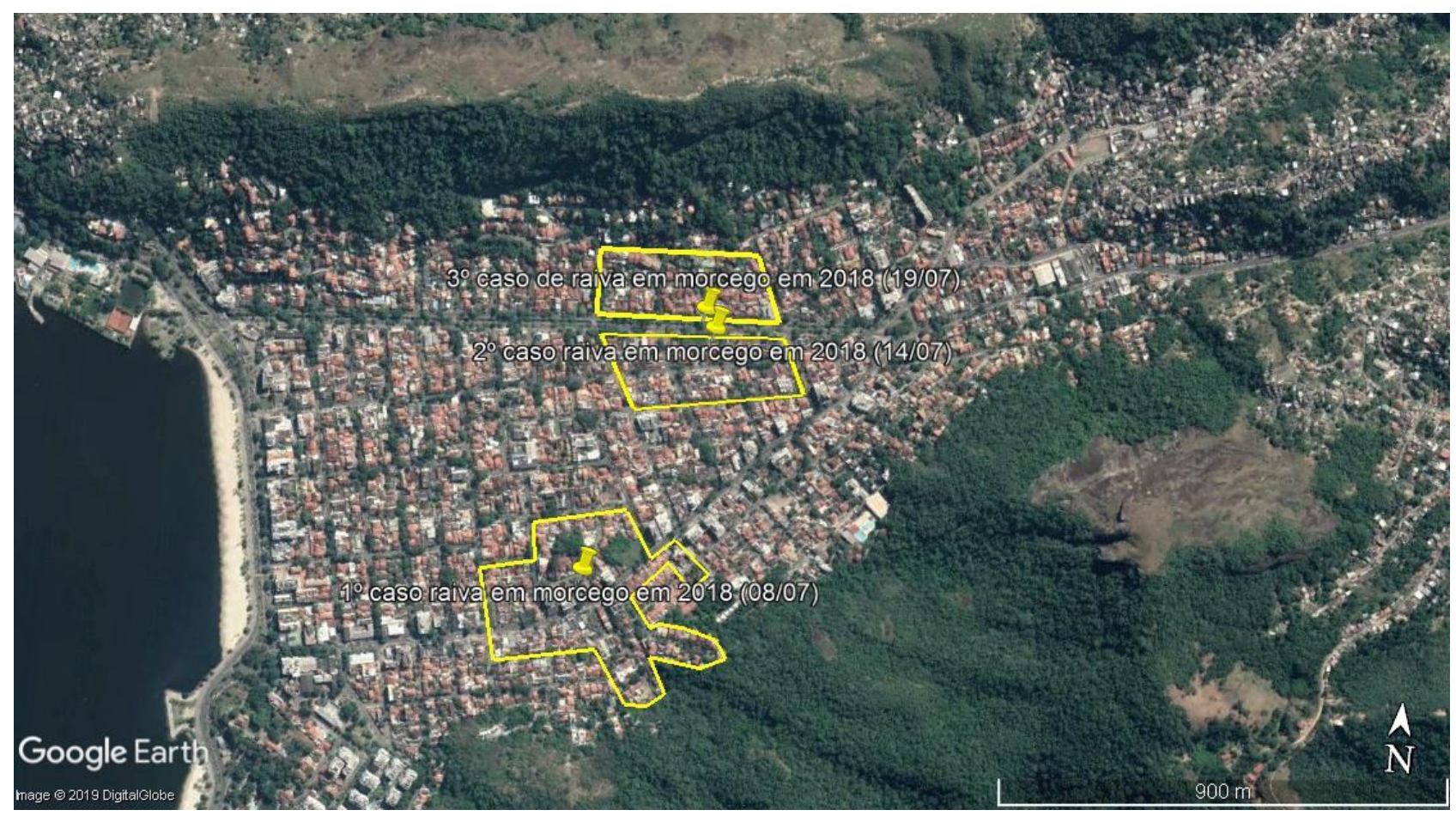

Figura 3. Perímetros ao redor dos casos positivos para raiva em morcegos onde foi efetuado bloqueio vacinal em cães e gatos no bairro São Francisco, Niterói, RJ, 2018.

O bairro vem apresentando grande quantidade de reclamações sobre morcegos ao Centro de Controle de Zoonoses nos últimos anos, sendo aquele com maior número de reclamações no período de 2014 a 2015 (Moutinho et al., 2018a; Moutinho et al., 2018b). Apresenta, também, frequentes casos de mordidas em animais por morcegos hematófagos, tendo sido registrados sete casos entre 2015 e 2018. Em 2015 houve registro de um caso de espoliação de humano em São Francisco, ocorrido a cerca de 157 metros do último caso positivo em morcego em 2018.
Cabe ressaltar que importância crescente vem sendo dada ao gênero Artibeus na questão da possibilidade de transmissão da raiva. Inclusive estudos filogenéticos demonstram que as cepas de vírus da raiva de ambas as espécies são intimamente associadas (Shoji et al., 2004; Kobayashi et al., 2005). Estudo desenvolvido no estado de São Paulo por Albas et al. (2011) concluiu que, dada a coabitação de morcegos hematófagos e não hematófagos, pode haver relação na disseminação do vírus da raiva entre esses grupos. Assim, a ocorrência dos referidos casos de espoliação por morcegos hematófagos serve de alerta para a possível transmissão da 
doença não somente por morcegos frugívoros, mas também os hematófagos.

De acordo com Queiroz et al. (2009) a confirmação da circulação viral em morcegos em áreas urbanas possibilita o desenvolvimento de ações visando a prevenção e o controle da enfermidade. Ainda que o Ministério da Saúde não recomende a ação de bloqueio vacinal no caso de raiva em morcegos, a municipalidade achou por bem desenvolvê-la, devido às características ecológicas do bairro e pelo fato da cobertura vacinal contra raiva vir se mantendo abaixo da meta desde 2010 (Moutinho et al., 2018b). Tal ação se justifica, ainda, pela incidência de atendimentos antirrábicos no município, com incidência média de 37,2 x 10 mil habitantes (Moutinho et al., 2018b). Não se pode, também, negligenciar a subnotificação dos acidentes envolvendo mordeduras e arranhaduras de animais possíveis transmissores de raiva, já que estudos vêm comprovando falhas nessas notificações, tanto em âmbito nacional, como no estado do Rio de Janeiro (Oliveira et al., 2010; Oliveira et al., 2012; Moutinho et al. 2015).

Por fim, como os morcegos que desenvolvem raiva tendem a não conseguir voar, passando a deambular (Acha e Szyfres, 2003), há sempre o risco do contato desses com cães e gatos, principalmente os últimos, naturalmente predadores. E, de acordo com o Ministério da Saúde, o risco de transmissão pelos morcegos é sempre alto (BRASIL, 2016).

Além dos animais domiciliados, como ocorrido no primeiro caso do presente estudo, há o risco inerente ao contato com animais não domiciliados. Quase todos os municípios brasileiros têm problemas no que tange aos animais não domiciliados (Vieira et al., 2006).

É importante destacar que, de acordo com o Ministério da Saúde, podem ser elencados como fatores de risco para a raiva, dentre outros, a presença de cães não domiciliados, a baixa cobertura vacinal canina, a presença de cães semidomiciliados (com acesso à rua na ausência de condutor), as alterações ambientais e a ocorrência de raiva em morcegos no município ou na vizinhança (BRASIL, 2009, BRASIL, 2016).

A situação relatada é muito preocupante do ponto de vista da saúde pública. Moutinho et al. (2018b) traça um quadro nebuloso em relação à presença de fatores condicionantes e determinantes para a ocorrência de raiva em humanos ou animais domésticos em Niterói.
Dentre eles, é importante destacar, além do que já foi discutido, a instabilidade no fornecimento de vacina antirrábica humana por parte do Ministério da Saúde, presença de primatas interagindo com a população humana e presença de morcegos na área urbana.

\section{Conclusão}

Os dados relatados e discutidos sugerem ter havido um surto de raiva em morcegos Artibeus sp. no bairro São Francisco, Niterói, em julho de 2018. A ocorrência de um evento desse em um bairro da área urbana de uma metrópole pode ser considerado um fator preocupante pela possibilidade de ocorrência de casos da doença em humanos ou animais domésticos, principalmente tendo em vista a existência dos demais fatores condicionantes e determinantes da ocorrência da enfermidade encontrados no município. Nesse sentido, esforços devem ser envidados pelo poder público, numa perspectiva de Saúde Única, no sentido de eliminar ou mitigar tais fatores, visando salvaguardar a saúde da população.

\section{Conflito de Interesse}

Os autores declaram não existir conflito de interesse.

\section{Referências}

Acha, P.N.; Szyfres, B. Zoonosis y enfermedades transmisibles comunes al hombre y a los animales. $3^{\text {rd }}$ ed. Washington: OPAS, 2003. 413p.

Albas, A.; Souza, E.A.N.; Picolo, M.R.; Favoretto, S.R.; Gama, A.R.; Sodré, M.M. Os morcegos e a raiva na região oeste do Estado de São Paulo. Revista da Sociedade Brasileira de Medicina Tropical, 44(2): 201205, 2011.

Bernardes Filho, F.; Martins, G.; Luchi, G.S.; Kac, B.K.; Nery, J.A.C.; Azulay-Abulafia, L.; Azulay, D.R. Multiple lesions by vampire bat bites in a patient in Niterói, Brazil - Case report. Anais Brasileiro de Dermatologia, 89(2): 340-343, 2014.

Bianconi, G.V.; Mikich, S.B.; Pedro, W.A. Movements of bats (Mammalia, Chiroptera) in Atlantic Forest remnants in Southern Brazil. Revista Brasileira de Zoologia, 23(4): 11991206, 2006.

BRASIL. Ministério da Saúde. Morcegos em áreas urbanas e rurais: manual de manejo e 
controle. Brasília: Fundação Nacional de Saúde, 1988. 117p.

BRASIL. Ministério da Agricultura, Pecuária e Abastecimento. Controle da raiva dos herbívoros: manual técnico. Brasília: MAPA, 2009. 124p.

BRASIL. Ministério da Saúde. Nota técnica $\mathbf{n}^{\mathbf{0}}$ 19/2012-CGTD/DEVEP/SVS/MS: Diretrizes da vigilância em saúde para atuação diante de casos de raiva em morcegos em áreas urbanas. 2012. Disponível em: <http://www.saude.pr.gov.br/arquivos/File/not a_tecnica_19_raiva.pdf $>$. Acesso em: 27 set. 2018.

BRASIL. Ministério da Saúde. Guia de vigilância em saúde. Brasília: Ministério da Saúde, 2016. 773p.

BRASIL. Ministério da Saúde. Situação epidemiológica: raiva 2018. Disponível em: <http://portalms.saude.gov.br/saude-de-az/raiva/situacao-epidemiologica $>$. Acesso em: 20 jan. 2019.

Brusco, A.R.; Tozato, H.C. Frugivoria na dieta de Artibeus lituratus Olfers, 1818 (Chiroptera, Phyllostomidae) no Parque do Ingá, Maringá / PR. Revista F@ pciência, 3(2): 19-29, 2009.

Cabral, C.C.; Morais, A.C.N.; Dias, A.V.A.B.; Araújo, M.G.; Moreira, W.C.; Mattos, G.L.M. Circulation of the rabies virus in nonhematophagous bats in the City of Rio de Janeiro, Brazil, during 2001-2010. Revista da Sociedade Brasileira de Medicina Tropical, 45(2): 180-183, 2012.

Costa, L.M.; Esbérard, C.E.L. Desmodus rotundus (Mammalia: Chiroptera) on the Southern Coast of Rio de Janeiro state, Brazil, Brazilian Journal of Biology, 71(3): 739-746, 2011.

Instituto Brasileiro de Geografia e Estatística IBGE. Censo de 2010. Disponível em: <https://censo2010.ibge.gov.br/sinopseporsetor es/?nivel=st/16>. Acesso em: 20 jan. 2019.

Instituto Brasileiro de Geografia e Estatística IBGE. Panorama: Niterói. 2019. Disponível em:

<https://cidades.ibge.gov.br/brasil/rj/niteroi/pa norama>. Acesso em: 23 jan. 2019.

Kobayashi, Y.; Sato, G; Shoji, Y.; Sato, T.; Itou, T.; Cunha, E.M.; Samara, S.I.; Carvalho, A.A.; Nociti, D.P.; Ito, F.H.; Sakai, T. Molecular epidemiological analysis of bat rabies viruses in Brazil. The Journal of Veterinary Medical Science, 67: 647-652, 2005.
Moutinho, F.F.B.; Nascimento, E.R.; Paixão, R.L. Raiva no Estado do Rio de Janeiro, Brasil: análise das ações de vigilância e controle no âmbito municipal. Ciência \& Saúde Coletiva, 20(2): 577-586, 2015.

Moutinho, F.F.B; Correa, D.M.S.; Serra, C.M.B.; Valente, L.C.M.; Borges, F.V.B.; Faria Neto, F. Caracterização dos atendimentos a reclamações sobre morcegos efetuadas ao centro de controle de zoonoses de Niterói, RJ (2014-2015). Hygeia, 14(28): 85-95, $2018 \mathrm{a}$.

Moutinho, F.F.B.; Borges, F.V.B.; Faria Neto, F.; Alves, C.B. Fatores determinantes e condicionantes para a ocorrência de raiva em Niterói, RJ, Brasil. Hygeia, 14(29): 54-64, 2018b.

Niterói. Decreto $\mathrm{n}^{0}$ 9.059/2003, de 22 de agosto de 2003. Disponível em: <http://pgm.niteroi.rj.gov.br/legislacao_pmn/2 003/DECRETOS/9059_Plano_de_Manejo_da_ Area_de_Protecao_Ambiental_do_Morro_da_ Viracao.pdf >. Acesso em: 20 jan. 2019.

Niterói. Plano Diretor de Niterói. Lei 1157/1992 alterada pela lei 2123/2004.Disponível em: <http://www.pgm.niteroi.rj.gov.br/leis/lei/Lei_ n1157_Plano_Diretor_Alterado_pela_Lei_212 3.pdf>. Acesso: 23 jan. 2019.

Oliveira, A.S.S.; Bezerra, F.F.M.; Azevedo, F.R.M.A. Descrição do perfil epidemiológico da raiva no Estado do Rio de Janeiro no período de 1981 a 2007. Revista Rede de Cuidados em Saúde, 4(2): 1-12, 2010.

Oliveira, V.M.R.; Pereira, P.L.L.; Silva, J.A.; Miranda, C.F.J.; Rodrigues, K.O.; Rodrigues, T.O.; Moreira, E.C. Mordedura canina e atendimento antirrábico humano em Minas Gerais. Arquivos Brasileiros de Medicina Veterinária e Zootecnia, 64(4): 891-898, 2012.

Organização Panamericana de Saúde - OPAS; Brasil. Ministério da Saúde. Avaliação do Programa Nacional de Controle da Raiva no Brasil. 2002. Disponível em < https://iris.paho.org/handle/10665.2/41202>.

Acesso em: 26 ago. 2019.

Pacheco, S.M.; Sodré, M.; Gama, A.R.; Bredt, A.; Sanches, E.M.C.; Marques, R.V.; Guimarães, M.M.; Bianconi, G.V. Morcegos urbanos: status do conhecimento e plano de ação para a conservação no Brasil. Chiroptera Neotropical, 16(1): 629-647, 2010.

Queiroz, L.H.; Carvalho, C.; Buso, D.S.; Ferrari, C.I.L.; Pedro, W. Perfil epidemiológico da 
raiva na região Noroeste do Estado de São Paulo no período de 1993 a 2007. Revista da Sociedade Brasileira de Medicina Tropical, 42(1): 9-14, 2009.

Shoji, Y.; Kobayashi, Y.; Sato, G.; Itou, T.; Miura, Y.; Mikami, T.; Cunha, E.M.; Samara, S.I.; Carvalho, A.A.; Nocitti, D.P.; Ito, F.H.; Kurane, I.; Sakai, T. Genetic characterization of rabies viruses isolated from frugivorous bat (Artibeus spp.) in Brazil. The Journal of Veterinary Medical Science, 66(10): 12711273, 2004.

Maia-Silva, C.; Silva, C.I.; Hrncir, M.; Queiroz, R.T.; Imperatriz-Fonseca, V.L. Guia de plantas visitadas por abelhas na Caatinga. Fortaleza: Fundação Brasil Cidadão, 2012. 98p.

Siqueira, A.C.; Ribeiro, E.A. Aguiar, M.V.P.; Souza, R.F.; Novaes, R.L.M.; Barros, A.A.M.; Pontes, J.A.L. Diversidade de quirópteros em inselberg da Mata Atlântica no sudeste brasileiro: Morro das Andorinhas, Niterói (RJ). In: Santos, S.M.G. (Org.). Biodiversidade e sociedade no Leste Metropolitano do Rio de Janeiro. Rio de Janeiro: UERJ, 2016. p.69-94.

Siqueira, J.C. Dispersão de espécies nativas na arborização urbana. Pesquisa Botânica, 70: 187-195, 2017.

Sodré, M.M.; Gama, A.R.; Almeida, M.F. Updated list of bat species positive for rabies in Brazil. Revista do Instituto de Medicina Tropical, 52(2): 75-81, 2010.

Uieda, W.; Harmani, N.M.S.; Silva, M.M.S. Raiva em morcegos insetívoros (Molossidae) do Sudeste do Brasil. Revista de Saúde Pública, 29(5): 292-297, 1995.

Van Der Pijl, L. Principles of dispersal in higher plants. $2^{\text {nd }}$ ed. New York: Springer-Verlag, 1972. 162p.

Vieira, A.M.L. (Org.). Programa de controle de cães e gatos do Estado de São Paulo. São Paulo: Secretaria de Estado de Saúde, 2006. $165 \mathrm{p}$.

Zortéa, M. Subfamília Stenodermatinae. In: Reis, N.R. (Org). Morcegos do Brasil. Londrina: Nélio R. dos Reis, 2007. p.107-128. 